\title{
Bending Vibration Suppression of a Flexible Multispan Shaft Using Smart Spring Support
}

\author{
Bo Peng, Rupeng Zhu, Miaomiao Li, and Ziyang Tang \\ College of Mechanical and Electrical Engineering, Nanjing University of Aeronautics and Astronautics, Nanjing 210016, China \\ Correspondence should be addressed to Rupeng Zhu; rpzhu@nuaa.edu.cn
}

Received 7 December 2016; Accepted 26 March 2017; Published 30 April 2017

Academic Editor: Francesco Ripamonti

Copyright (C) 2017 Bo Peng et al. This is an open access article distributed under the Creative Commons Attribution License, which permits unrestricted use, distribution, and reproduction in any medium, provided the original work is properly cited.

\begin{abstract}
Because the flexible multispan shaft in large machines often rotates at supercritical speed, it is desirable to find ways to suppress the resulting bending vibration. In this paper, a novel type of support structure is proposed and investigated, which can suppress the bending vibration using dry friction. This approach is called Smart Spring support (SMSS). A dynamic model for the multispan shaft with SMSS is developed. The relationship between the vibration suppression effect and the control parameters of the SMSS is obtained through a numerical example involving a helicopter tail drive shaft. A structure of the SMSS is designed and examined with a rotor test. The results demonstrate that the SMSS has a significant effect on bending vibration suppression of flexible multispan shafts. The vibration-reduction ratio of the peak amplitude reaches $57.2 \%$ in the numerical example and $45.2 \%$ in the rotor test.
\end{abstract}

\section{Introduction}

Multispan shafts are widely used in aviation, vehicles, ships, and large generator units. They are an important part of the transmission chain of many large machines. Together with the trend towards flexible and high-speed rotors, the rotating speed of multispan shafts often exceeds their critical speed, and the problem of supercritical bending vibration becomes increasingly prominent. Therefore, finding an effective bending vibration control method is highly desirable.

The majority of previous studies focused on changing the stiffness and damping characteristics of the multispan shaft supports, using passive vibration dampers to suppress bending vibration. Examples include flexible support and squeeze film dampers (SFD), metal-rubber dampers (MRD), or polymer-based composite structures [1]. However, the structure of a multispan shaft is complex, and its behavior is difficult to predict for different assembly and working conditions. This makes the design of a passive vibration absorber difficult. Active vibration suppression methods are capable of changing the instantaneous control force or the dynamic characteristics of the structure based on the realtime vibration situation by using external energy sources [2]. This has a unique advantage for attenuating the bending vibration faster, compared to passive vibration dampers.
The piezoelectric actuator (PZTA) is low-cost, lightweight, and easy-to-implement [3]. As a result, it is widely used in active control technologies. Active vibration suppression technologies based on the PZTA have strong environmental adaptability, and they can be used in an effective manner to suppress vibration significantly over a broadband of frequencies [4]. However, presently, most of them are used to reduce the amplitude or vibration force by restraining the excitation force directly [5-7]. The dynamic displacement of the PZTA is generally on a micron level, which implies a restriction on the direct vibration control.

The Smart Spring is a semiactive control concept to suppress vibration based on the PZTA. It does not use the PZTA to counteract the excitation loads but adaptively varies the stiffness, damping, and mass of the dynamic system [4]. Hence, the Smart Spring system does not need a complex displacement amplification device and high actuation voltages, which makes it easier to implement.

Nitzsche and other researchers published most of the current literature on Smart Springs. Their research on Smart Springs mainly focuses on the vibration control of the helicopter rotor [8]. In 2009, Oxley et al. modeled the Smart Spring as a replacement for the conventional rotor pitch link to attenuate airframe vibration in helicopters [9]. 
Then, in 2012, Nitzsche and Fred designed a type of Active Pitch Link (APL) based on the Smart Spring concept and obtained experimental closed-loop results using a stateswitching control algorithm [10]. After that, in 2013, Nitzsche et al. performed experimental and numerical simulation with an open-loop control law applied to an APL and observed a significant reduction of the amplitude of the blade [11]. In 2015, Arras et al. carried out the dynamic identification of a reduced-scale helicopter blade system that uses the APL for vibration control from FRFs measurements [12].

The above research focused on the vibration reduction of helicopter rotor blades. There is little research of the bending vibration suppression of shafts. In 2011, Cavalini et al. established a discrete dynamic model for shafts with a Smart Spring mechanism and performed numerical simulation using on-off control strategies [13]. In this study, however, the effects of dry friction were neglected, and the vibrationreduction effect is not very strong. Therefore, current research on bending vibration suppression of shafts with Smart Spring is still at an early stage. An accurate dynamic model to describe the system and necessary experimental verification is still in need.

In this paper, we apply the Smart Spring to the support structure of a flexible multispan shaft, known as the Smart Spring support (SMSS). The structure of the paper is as follows. First, a novel continuous bending vibration dynamics model of the flexible multispan shaft with a SMSS is introduced. Then, the dynamic differential equation with consideration of the effect of dry friction is derived. In the next section, we perform a numerical simulation of the supercritical bending vibration suppression, using the SMSS, for a helicopter tail shaft. We designed the structure of a type of SMSS, with which we will verify the effect of vibration suppression during rotor testing. Overall, a theoretical model and an experimental reference for the design of an SMSS is provided.

\section{Dynamic Model}

2.1. Model Simplification. The Smart Spring system is shown in Figure 1. The system is composed of a primary spring, an active spring, and a PZTA. There is friction coupling between the primary spring and the active spring. The movements of these two springs are independent of each other until a control voltage is applied to the PZTA. Then, the control force $N_{t}$ is generated on the friction surface. If there is a relative motion between the primary spring and the active spring, the sliding friction force $F_{d}$ is induced by the control force $N_{t}$, which will dissipate the energy of the system. This procedure is called Damping Control. With the increase of the control force $N_{t}$, the active spring will be gradually combined with the primary spring via viscosity forces. When the control force $N_{t}$ is large enough, these two springs are fully integrated together, and the natural frequency of the coupling system is far higher than that of the original primary spring for the common system parameters [14]. This procedure is called Rigidity Control.

As illustrated in Figure 2, the research aim of this paper is a flexible multispan shaft with hinged supports at both

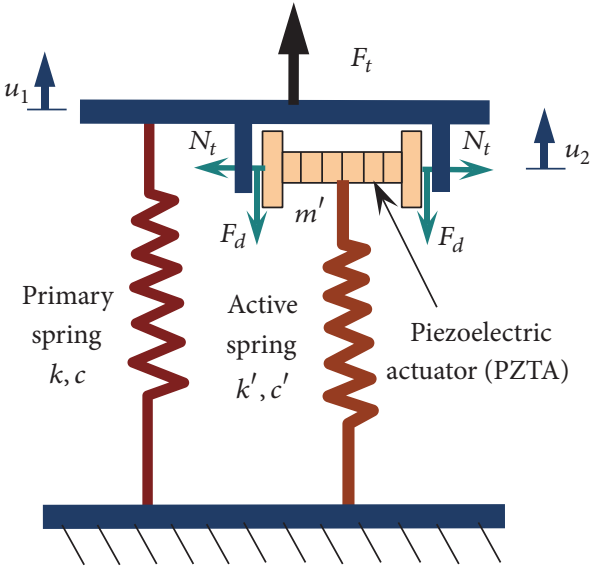

Figure 1: The Smart Spring system [4].

ends and elastic supports in the middle. Some of the elastic supports are provided with the Smart Spring vibration damping system, SMSS, as mentioned above. We call the primary spring-shaft the main support, and the active spring-PZTA the auxiliary support. The influence of the gyro moment on the bending vibration of the shaft cannot be ignored because of the high rotation speed. Therefore, the shaft section is equivalent to the Rayleigh beam, but the influence of the gyro moment is considered as well. In addition, we assume that the shaft and its supports are isotropic. Thus, the dynamic model of the system can be projected to two orthogonal directions, and the model parameters are the same in these two directions, except for gravity.

The origin $O_{0}$ of the inertial coordinate system $O_{0} x_{0} y_{0} z_{0}$ is located at the centroid point at the left end of the shaft in Figure 2. The displacements of the shaft section center along the $x_{0}$ - and $y_{0}$-axis are $u_{z b}$ and $v_{z b}$, respectively, where the abscissa value is $z_{b}$. The eccentricity of the shaft section is $e_{z b}$, the initial phase angle is $\phi_{e 0}$, and the rotating speed is $\omega_{\phi}$. When the shaft rotates, the unbalanced excitation, which is caused by the eccentric mass, produces the dynamic bending deflection of the shaft. The shaft will spin around the $z_{0}$-axis besides rotation, and the shaft section will deviate from the original plane. The spatial motion of the shaft section can be separated into translation of the base point and the fixedpoint rotation around the base point. The coordinate system of the shaft section in spatial motion is shown in Figure 3, where $O x_{1} y_{1} z_{1}$ is the translational coordinate system with the basis of the base point $O . \mathrm{Ox}_{2} y_{2} z_{2}$ is the transition coordinate system and $O x y z$ is the rotational coordinate system. The coordinate of the base point $O$ in $O_{0} x_{0} y_{0} z_{0}$ is $\left(u_{z b}, v_{z b}, z_{b}\right)$ and the Euler angles of $O x y z$ deflecting from $O x_{1} y_{1} z_{1}$ are $(\psi, \theta, \phi)$.

2.2. Equation Deduction. The motion of the shaft in Figure 2 can be described using the second Lagrange equation as

$$
\frac{d}{d t}\left(\frac{\partial T}{\partial \dot{q}_{j}}\right)-\frac{\partial T}{\partial q_{j}}+\frac{\partial U}{\partial q_{j}}=Q_{j} \quad(j=1, \ldots, n),
$$



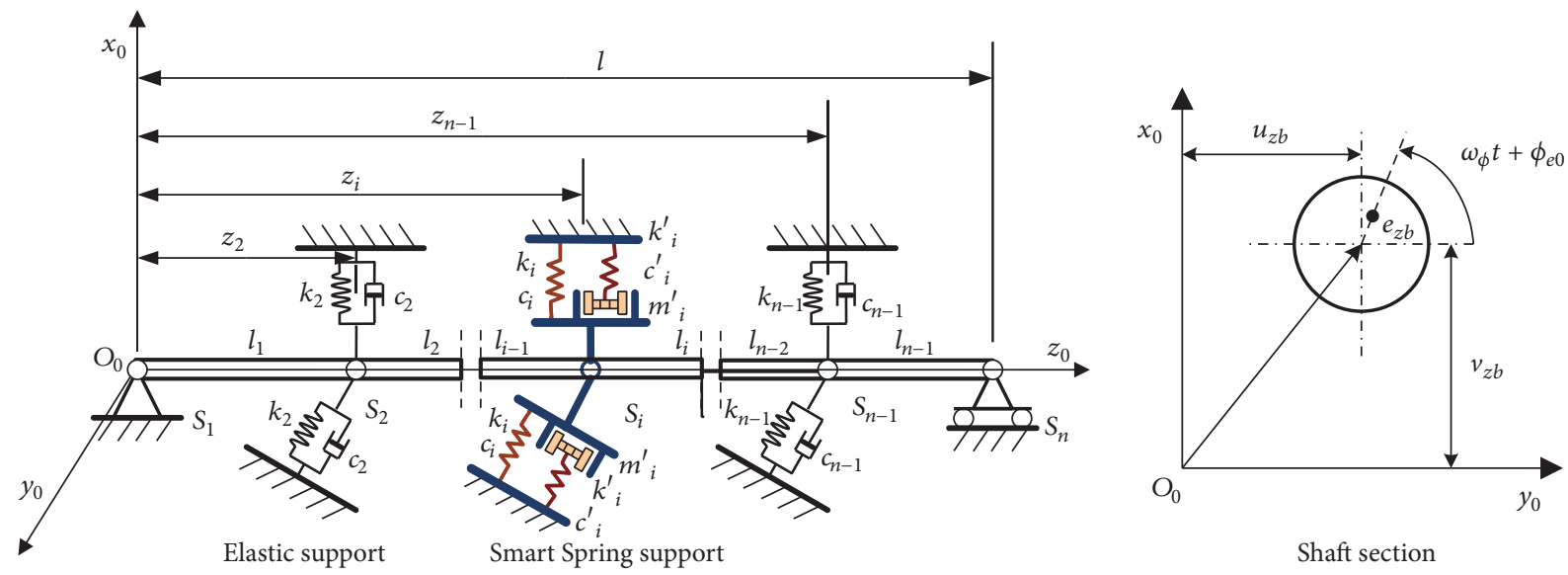

FIGURE 2: Flexible multispan shaft with the SMSS.

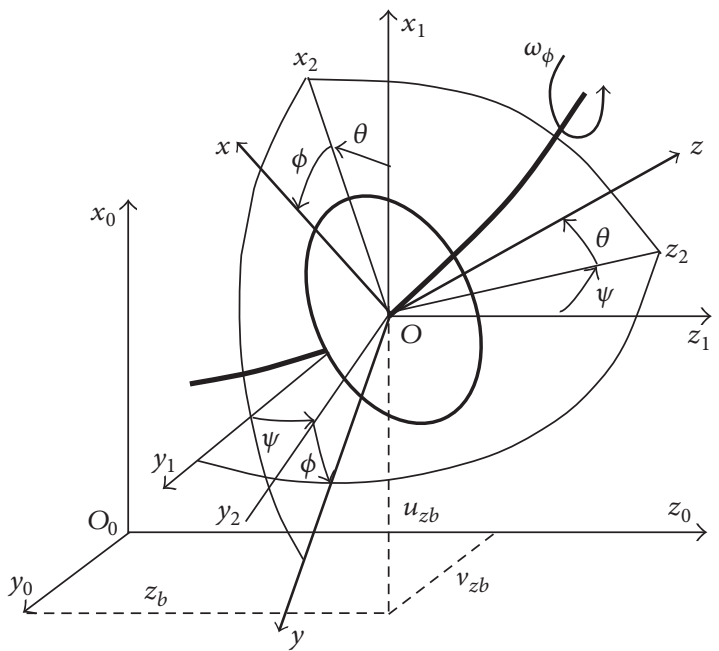

Figure 3: Coordinate system for the shaft element in motion.

where $T$ is the kinetic energy of the system, $U$ is the potential energy, $Q_{j}$ is the generalized force acting on the system, $q_{j}$ is the generalized coordinate, and $n$ is the total degree of freedom.

The shaft section in Figure 3 can be equivalent to a thin disk for the analysis of the kinetic energy. The kinetic energy of the disk can be divided into two parts: translational energy and rotational energy. We define the mass of the disk as $m_{d}$, and the moments of inertia of the disk relative to the axes in $O x y z$ as $I_{d x}, I_{d y}$, and $I_{d z}$, respectively, where $I_{d x}=I_{d y}$ because of the isotropy of the shaft. As the Euler angles $\psi, \theta$ are very small, we assume that $\cos \theta \approx 1$ and $\sin \theta \approx \theta$. The kinetic energy of the disk without the high-order microquantity can be written as

$$
\begin{aligned}
T_{d}= & \frac{1}{2} m_{d}\left(\dot{u}_{z b}^{2}+\dot{v}_{z b}^{2}\right)+\frac{1}{2} I_{d x}\left(\dot{\psi}^{2}+\dot{\theta}^{2}\right) \\
& +\frac{1}{2} I_{d z}\left(\omega_{\phi}^{2}+2 \omega_{\phi} \dot{\psi} \theta\right) .
\end{aligned}
$$

The kinetic energy of the entire shaft in Figure 2 can be obtained by integrating (2) along the length of the shaft:

$$
\begin{aligned}
T_{s} & =\frac{\rho A}{2} \int_{0}^{l}\left(\left(\dot{u}_{z b}-e_{z b} \omega_{\phi} \sin \left(\omega_{\phi} t+\phi_{e 0}\right)\right)^{2}\right. \\
& \left.+\left(\dot{v}_{z b}+e_{z b} \omega_{\phi} \cos \left(\omega_{\phi} t+\phi_{e 0}\right)\right)^{2}\right) d z_{b}+\frac{\rho I}{2} \\
& \cdot \int_{0}^{l}\left(\dot{\psi}^{2}+\dot{\theta}^{2}\right) d z_{b}+\rho I l \omega_{\phi}^{2}+2 \rho I \omega_{\phi} \int_{0}^{l} \dot{\psi} \theta d z_{b},
\end{aligned}
$$

where $A$ is the area of the shaft section, $\rho$ is the density, $I$ is the moment of inertia of the shaft section relative to its center, and the last term in the equation is caused by the gyroscopic effect. The Euler angles $\psi, \theta$ can be described by $\theta=\partial u_{z b} / \partial z_{b}$ and $\psi=-\partial v_{z b} / \partial z_{b}$ as their microscale.

The potential energy of the shaft is mainly composed of two parts: the strain energy induced by the shaft bending and the gravitational potential energy under gravitational acceleration, $g$. The potential energy of the entire shaft can be obtained using Hooke's law:

$$
\begin{aligned}
U_{s}= & \frac{\mathrm{EI}}{2} \int_{0}^{l}\left[\left(\frac{\partial^{2} u_{z b}}{\partial z_{b}^{2}}\right)^{2}+\left(\frac{\partial^{2} v_{z b}}{\partial z_{b}^{2}}\right)^{2}\right] d z_{b} \\
& +\int_{0}^{l} \rho A g\left[u_{z b}+e_{z b} \cos \left(\omega_{\phi} t+\phi_{e 0}\right)\right] d z_{b} .
\end{aligned}
$$

In the case, where $S_{i}$ in Figure 2 is an elastic support, the virtual work on the shaft produced by the support can be written as the following equation that neglects the bending effect:

$$
\begin{aligned}
\delta W_{B, i}= & {\left[-k_{i} u\left(z_{i}\right)-c_{i} \dot{u}\left(z_{i}\right)\right] \delta u\left(z_{i}\right)-k_{i} v\left(z_{i}\right) \delta v\left(z_{i}\right) } \\
& -c_{i} \dot{v}\left(z_{i}\right) \delta v\left(z_{i}\right)=Q_{u, i} \delta u\left(z_{i}\right)+Q_{v, i} \delta v\left(z_{i}\right),
\end{aligned}
$$

where $Q_{u, i}$ and $Q_{v, i}$ are the equivalent generalized forces of the elastic support in $x_{0}$ and $y_{0}$ directions, respectively, and $z_{i}$ is the coordinate of the installation position for the elastic support. 
If $S_{i}$ is a SMSS, the virtual work on the shaft produced by the support can be written as

$$
\begin{aligned}
\delta W_{B, i}= & -\left[k_{i} u\left(z_{i}\right)+c_{i} \dot{u}\left(z_{i}\right)+F_{d u, i}\right] \delta u\left(z_{i}\right) \\
& -\left[k_{i} v\left(z_{i}\right)+c_{i} \dot{v}\left(z_{i}\right)+F_{d v, i}\right] \delta v\left(z_{i}\right) \\
= & Q_{u, i} \delta u\left(z_{i}\right)+Q_{v, i} \delta v\left(z_{i}\right),
\end{aligned}
$$

where $F_{d u, i}$ and $F_{d v, i}$ are the sliding friction forces between the friction surfaces of the main support and the auxiliary support in $x_{0}$ and $y_{0}$ directions, respectively:

$$
\begin{aligned}
& F_{d u, i} \\
& = \begin{cases}\operatorname{sgn}\left(v_{u r, i}\right) \mu_{d} N_{t, i}, & v_{u r, i} \neq 0, \\
F_{u s u m, i}, & \left|F_{u s u m, i}\right|<\mu_{s} N_{t, i}, \quad v_{u r, i}=0, \\
\operatorname{sgn}\left(F_{u s u m, i}\right) \mu_{s} N_{t, i}, & \left|F_{u s u m, i}\right| \geq \mu_{s} N_{t, i}, \quad v_{u r, i}=0,\end{cases} \\
& F_{u s u m, i}=m_{i}^{\prime} \ddot{u}_{i}^{\prime}+k_{i}^{\prime} u_{i}^{\prime}+c_{i}^{\prime} \dot{u}_{i}^{\prime}, \\
& F_{d v, i} \\
& = \begin{cases}\operatorname{sgn}\left(v_{v r, i}\right) \mu_{d} N_{t, i}, & v_{v r, i} \neq 0, \\
F_{v s u m, i}, & \left|F_{v s u m, i}\right|<\mu_{s} N_{t, i}, \quad v_{v r, i}=0, \\
\operatorname{sgn}\left(F_{v s u m, i}\right) \mu_{s} N_{t, i}, & \left|F_{v s u m, i}\right| \geq \mu_{s} N_{t, i}, \quad v_{v r, i}=0, \\
F_{v s u m, i}=m_{i}^{\prime} \ddot{v}_{i}^{\prime}+k_{i}^{\prime} v_{i}^{\prime}+c_{i}^{\prime} \dot{v}_{i}^{\prime},\end{cases}
\end{aligned}
$$

where $v_{u r, i}$ and $v_{v r, i}$ are the relative speed between friction surfaces of the main support and the auxiliary support in $x_{0}$ and $y_{0}$ directions, respectively. If these are zero, the SMSS will be under Rigidity Control; otherwise, the SMSS would be under Damping Control. $F_{u s u m, i}$ and $F_{v s u m, i}$ are the restoring forces, which depend on the motion state of the auxiliary support. $u_{i}^{\prime}$ and $v_{i}^{\prime}$ are the radial displacements of the auxiliary support. $\mu_{d}$ is the dynamic friction coefficient, and $\mu_{s}$ is the static friction coefficient.

After substituting (3), (4), (5), and (6) into (1), the dynamic equation of the system can be formulated as

$$
\begin{aligned}
& \rho A \frac{\partial^{2} u_{z b}}{\partial t^{2}}+\mathrm{EI} \frac{\partial^{4} u_{z b}}{\partial z_{b}^{4}}-\rho I \frac{\partial^{4} u_{z b}}{\partial z_{b}{ }^{2} \partial t^{2}}-2 \rho I \omega_{\phi} \frac{\partial^{3} v_{z b}}{\partial z_{b}{ }^{2} \partial t} \\
& =\rho A e_{z b} \omega_{\phi}^{2} \cos \left(\omega_{\phi} t+\phi_{e 0}\right)-\rho A g+Q_{u}, \\
& \rho A \frac{\partial^{2} v_{z b}}{\partial t^{2}}+\mathrm{EI} \frac{\partial^{4} v_{z b}}{\partial z_{b}^{4}}-\rho I \frac{\partial^{4} v_{z b}}{\partial z_{b}{ }^{2} \partial t^{2}}+2 \rho I \omega_{\phi} \frac{\partial^{3} u_{z b}}{\partial z_{b}{ }^{2} \partial t} \\
& =\rho A e_{z b} \omega_{\phi}^{2} \sin \left(\omega_{\phi} t+\phi_{e 0}\right)+Q_{v} .
\end{aligned}
$$

Equation (8) is a partial differential equation and its solution space has infinite dimensions. The Galerkin method is used to simplify (8) into a finite number of ordinary differential equations. In the constitutional equation (9),
$W_{r}\left(z_{b}\right)$ is the $r$ th order mode shape function of the hinged beam and $q_{u r}(t)$ and $q_{v r}(t)$ are the generalized coordinates.

$$
\begin{aligned}
& u_{z b}\left(z_{b}, t\right)=\sum_{r=1}^{+\infty} W_{r}\left(z_{b}\right) q_{u r}(t), \\
& v_{z b}\left(z_{b}, t\right)=\sum_{r=1}^{+\infty} W_{r}\left(z_{b}\right) q_{v r}(t) .
\end{aligned}
$$

After substituting (9) into (8) and integrating it over the length of the shaft after multiplying $W_{r}\left(z_{b}\right)$ on both sides of the equation, we can obtain the ordinary differential dynamic equations for the shaft using the orthogonality of its mode shape functions:

$$
\begin{aligned}
& M_{r} \ddot{q}_{u r}+K_{r} q_{u r}-\omega_{\phi} G_{y r} \dot{q}_{v r} \\
& =m_{e} e_{z b} \omega_{\phi}^{2} \cos \left(\omega_{\phi} t+\phi_{e 0}\right)-F_{G}+Q_{u}^{\prime}, \\
& M_{r} \ddot{q}_{v r}+K_{r} q_{v r}+\omega_{\phi} G_{y r} \dot{q}_{u r} \\
& =m_{e} e_{z b} \omega_{\phi}^{2} \sin \left(\omega_{\phi} t+\phi_{e 0}\right)+Q_{v}^{\prime},
\end{aligned}
$$

where $M_{r}=\rho A \int_{0}^{l} W_{r}^{2} d z_{b}-\rho I \int_{0}^{l} W_{r} W_{r}^{\prime \prime} d z_{b}, G_{y r}=$ $2 \rho I \int_{0}^{l} W_{r} W_{r}^{\prime \prime} d z_{b}, F_{G}=\rho A g \int_{0}^{l} W_{r} d z_{b}, m_{e}=\rho A \int_{0}^{l} W_{r} d z_{b}$, $Q_{u}^{\prime}=\sum_{i=1}^{n}\left[\left(-k_{i} q_{u r}-c_{i} \dot{q}_{u r}\right) W_{r}^{2}\left(z_{i}\right)-F_{d q u, i} W_{r}\left(z_{i}\right)\right]$, and $Q_{v}^{\prime}=$ $\sum_{i=1}^{n}\left[\left(-k_{i} q_{v r}-c_{i} \dot{q}_{v r}\right) W_{r}^{2}\left(z_{i}\right)-F_{d q v, i} W_{r}\left(z_{i}\right)\right]$.

When $S_{i}$ is an elastic support, $F_{d q u, i}=F_{d q v, i}=0$.

When $S_{i}$ is a SMSS, then

$$
\begin{aligned}
& F_{d q u, i}
\end{aligned}
$$

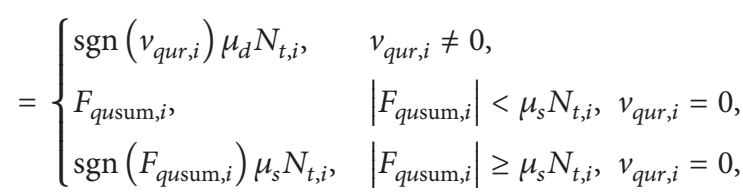

$$
\begin{aligned}
& F_{u s u m, i}=W_{r}\left(z_{i}\right)\left[m_{i}^{\prime} \ddot{q}_{u r}+k_{i}^{\prime}\left(q_{u r}+q_{u r 0}\right)+c_{i}^{\prime} \dot{q}_{u r}\right] \text {, } \\
& v_{q u r, i}=W_{r}\left(z_{i}\right) \dot{q}_{u r}-\dot{u}_{i}^{\prime}, \\
& F_{d q v, i} \\
& = \begin{cases}\operatorname{sgn}\left(v_{q v r, i}\right) \mu_{d} N_{t, i}, & v_{q v r, i} \neq 0, \\
F_{q v s u m, i}, & \left|F_{q v s u m, i}\right|<\mu_{s} N_{t, i}, \quad v_{q v r, i}=0, \\
\operatorname{sgn}\left(F_{q v s u m, i}\right) \mu_{s} N_{t, i}, & \left|F_{q v s u m, i}\right| \geq \mu_{s} N_{t, i}, \quad v_{q v r, i}=0,\end{cases} \\
& F_{v s u m, i}=W_{r}\left(z_{i}\right)\left[m_{i}^{\prime} \ddot{q}_{v r}+k_{i}^{\prime}\left(q_{v r}+q_{v r 0}\right)+c_{i}^{\prime} \dot{q}_{v r}\right] \text {, } \\
& v_{q v r, i}=W_{r}\left(z_{i}\right) \dot{q}_{v r}-\dot{v}_{i}^{\prime} .
\end{aligned}
$$

Equations (10) are ordinary differential equations with time-varying parameters, which can be solved using the variable step Runge Kutta method using numerical software. After substituting the solution of $q_{u r}$ and $q_{v r}$ into (9), the bending vibration response of the shaft for unbalanced excitation can be obtained. 
TABLE 1: Typical parameters of a helicopter tail-shaft.

\begin{tabular}{lc}
\hline Properties & Value $/$ unit \\
\hline$\rho$ & $2800 /\left(\mathrm{kg} \cdot \mathrm{m}^{-3}\right)$ \\
$E$ & $7 \times 10^{10} / \mathrm{Pa}$ \\
$G$ & $2.7 \times 10^{10} / \mathrm{Pa}$ \\
$D$ & $90 / \mathrm{mm}$ \\
$d$ & $84 / \mathrm{mm}$ \\
$l$ & $3.1 / \mathrm{m}$ \\
$l_{1}$ & $0.85 / \mathrm{m}$ \\
$l_{2}, l_{3}, l_{4}$ & $\left.0.75 / \mathrm{m}^{-1}\right)$ \\
$k_{1}, k_{5}$ & $1.15 \times 10^{7} /\left(\mathrm{N} \cdot \mathrm{m}^{-1}\right)$ \\
$k_{2}, k_{3}, k_{4}$ & $1.5 \times 10^{5} /\left(\mathrm{N} \cdot \mathrm{m}^{-1}\right)$ \\
$c_{1}, c_{5}$ & 0 \\
$c_{2}, c_{3}, c_{4}$ & $20 /\left(\mathrm{N} \cdot \mathrm{s} \cdot \mathrm{m}^{-1}\right)$ \\
$e_{z b}$ & $0.1 / \mathrm{mm}$ \\
$n_{\text {work }}$ & $4200 /\left(\mathrm{r} \cdot \mathrm{min}^{-1}\right)$ \\
\hline
\end{tabular}

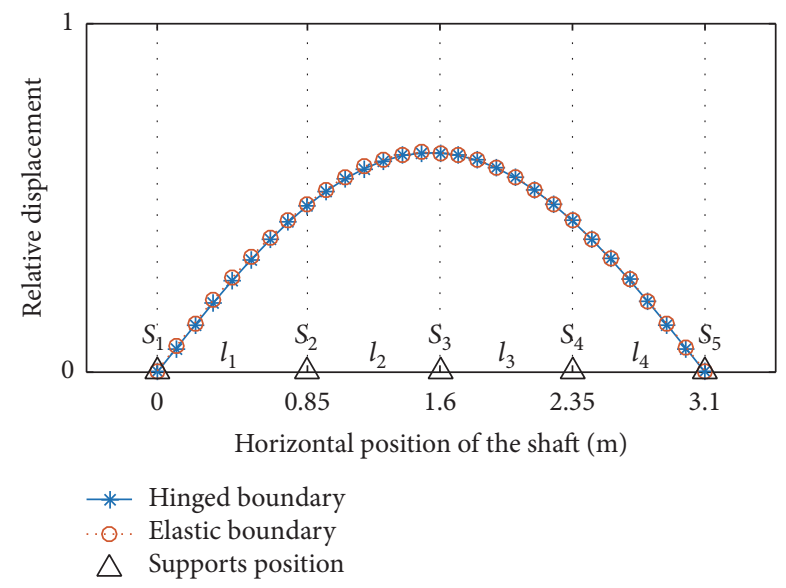

FIGURE 4: 1st mode shape with hinged and elastic boundaries of the helicopter tail shaft.

\section{Example of the Helicopter Tail Shaft}

3.1. Parameters of the Shaft. The helicopter tail shaft is a typical multispan shaft, which can be simplified into a combination of continuous hollow shaft sections and supports. A set of typical parameters for the helicopter tail shaft is selected in Table 1, on the basis that the dynamic response calculation of the shaft and the effect of the bending vibration suppression of the SMSS can be carried out.

The approximate critical speed of the tail shaft can be calculated using the transfer matrix method, where the 1st critical speed is $3179 \mathrm{RPM}$, and the 2nd critical speed is 6562 RPM. The operating speed of the tail shaft $n_{\text {work }}=$ 4200 RPM falls between the 1st and 2 nd order critical speeds. Hence, the tail shaft is flexible. The mode shape of the tail drive shaft can be obtained using the transfer matrix method. The 1st mode shapes of the tail shaft are very close with different boundary conditions in Figure 4. This is because the stiffness of the supports at both ends of the tail shaft is much larger than that of the middle supports. Therefore, the tail shaft can be simplified as a hinged beam model, similar to that in Figure 2.

The SMSS is installed at position $S_{3}$ of the maximum amplitude in the 1st mode shape. The parameters of the auxiliary support are $k_{i}^{\prime}=1 \times 10^{5} \mathrm{~N} \cdot \mathrm{m}^{-1}, c^{\prime}{ }_{i}=0$, and $m^{\prime}{ }_{i}$ $=1.5 \mathrm{~kg}$. The dynamic friction coefficient $\mu_{d}=0.1$ and the static friction coefficient $\mu_{s}=0.15$. The tail shaft starts to accelerate from rest with the angular acceleration $\alpha=$ $146.6 \mathrm{rad} / \mathrm{s}^{2}$, which takes $3 \mathrm{sec}$ to reach operating speed. After substituting the parameters in Table 1 into (10), we obtain the supercritical bending vibration response of the tail shaft. For better comparison, the time-domain response results obtained in this section are all at the position $z_{b}=1.6 \mathrm{~m}$.

3.2. Simulation Results and Analysis. The supercritical bending vibration response of the tail shaft in the $x_{0}$ direction, for different control forces $N_{t}$ of the SMSS, is shown in Figure 5. Considering that the trends of the change of the vibration amplitude in $x_{0}$ and $y_{0}$ directions are generally identical, only the vibration amplitude $u_{z b}$ in the $x_{0}$ direction is given in Figure 5. The axis orbits at its operating speed for different control forces $N_{t}$ of the SMSS (see Figure 6). The peak vibration-reduction ratio $\eta_{p}$ is defined as a percentage of the amplitude reduction of the bending vibration response for the control force $N_{t}$. The curves for $N_{t}$ and $\eta_{p}$ are shown in Figure 7. The critical speed $n_{c}$ of the tail shaft can be obtained by multiplying the angular acceleration $\alpha$ with the time $t_{p}$ of the peak. The curves for $N_{t}$ and $n_{c}$ are shown in Figure 8.

The peak amplitude of the tail shaft decreases first and increases later with the increase of the control force $N_{t}$, which reaches the minimum value when $N_{t}=250 \mathrm{~N}$ (see Figure 5). At this point, the peak vibration-reduction ratio $\eta_{p}$ reaches $57.2 \%$ in Figure 7 . After that, $\eta_{p}$ only becomes smaller, even if the control force $N_{t}$ is increased. The position of the peak amplitude shifts left first, with increasing $N_{t}$, because of the introduction of dry friction damping. When $N_{t}$ is large enough, the influence of damping of the auxiliary support is offset by its stiffness effect, and the position of the peak amplitude starts to shift right. It can be seen in Figure 8 that the position of the peak amplitude is farthest from the operating speed when $N_{t}=250 \mathrm{~N}$, and the critical speed $n_{c}$ reaches its minimum of $3339 \mathrm{RPM}$ at this point.

In Figure 6, the center track of the tail shaft is circular with a small control force $N_{t}$, and its associated radius is becoming smaller while $N_{t}$ increases. We suggest that the SMSS is in the state of Damping Control here. When the control force $N_{t}$ reaches $250 \mathrm{~N}$, the radius of the center track reaches its minimum. With increasing $N_{t}$, the center track becomes more irregular. We suggest that the two friction surfaces of the SMSS no longer experience pure sliding friction here but a Stick-Slip State, between sliding and sticking, which has a strong nonlinear characteristic. When the control force $N_{t}$ reaches $1000 \mathrm{~N}$, the center track returns to the circle again because the two friction surfaces of the SMSS have been fully integrated. This means the SMSS is in the state of Rigidity Control, and the radius of the center track becomes larger because the critical speed of the tail shaft with its higher supporting stiffness is closer to the operating speed. 


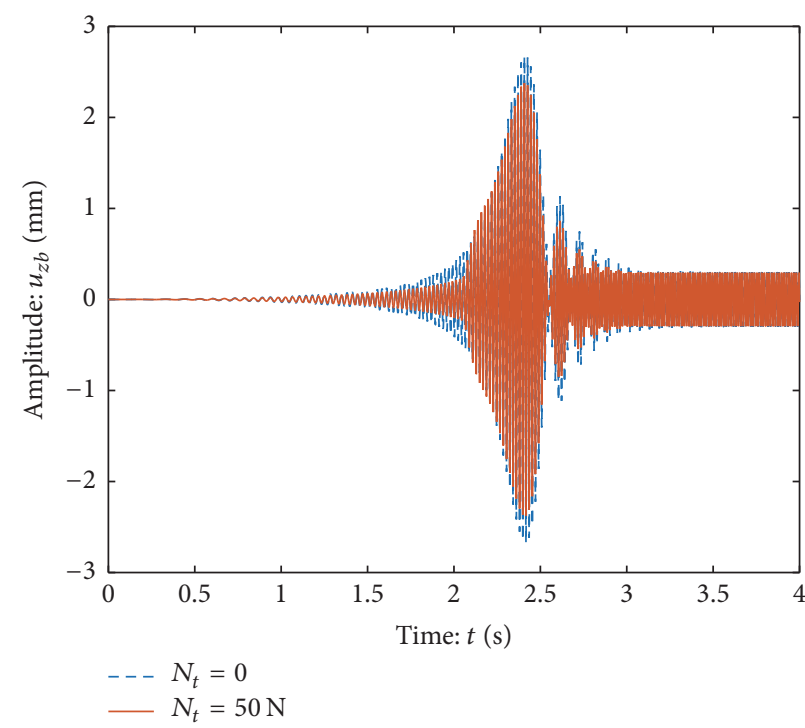

(a) $N_{t}=50 \mathrm{~N}$

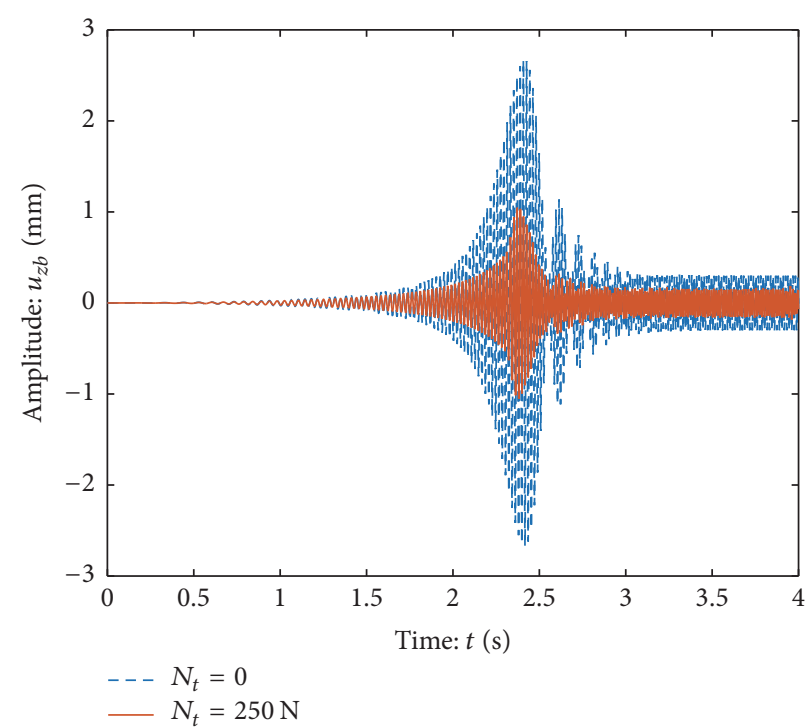

(c) $N_{t}=250 \mathrm{~N}$

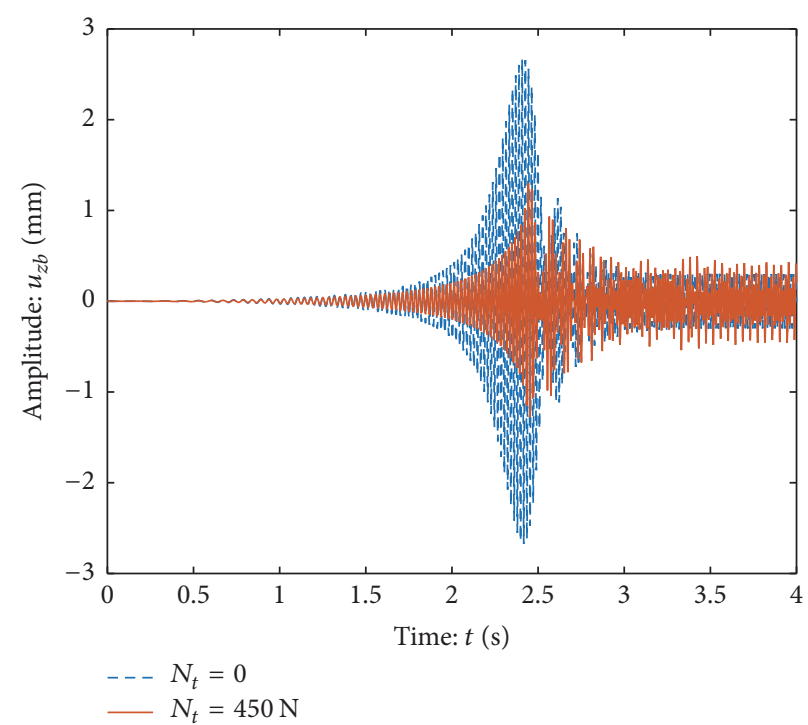

(e) $N_{t}=450 \mathrm{~N}$

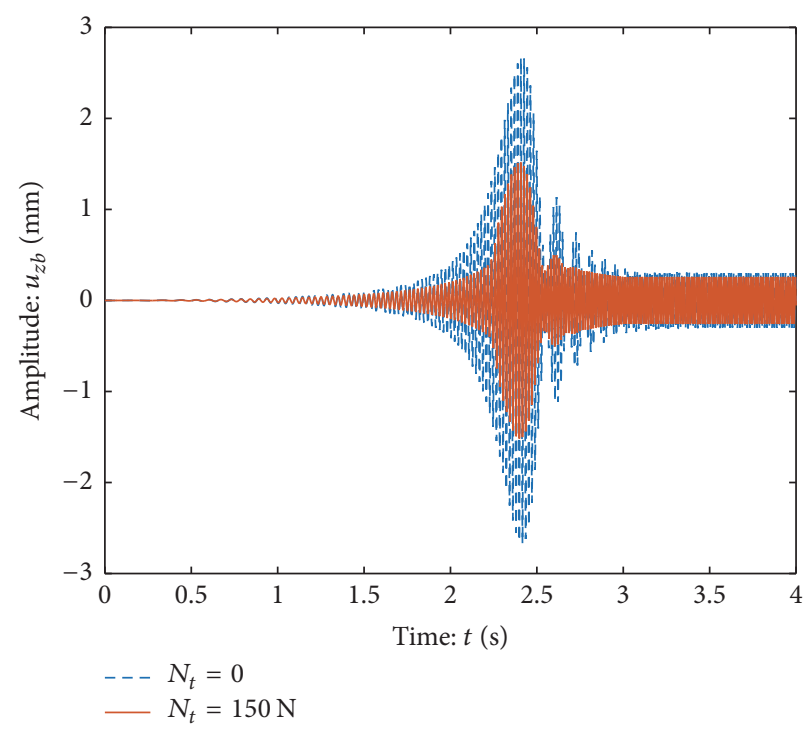

(b) $N_{t}=150 \mathrm{~N}$

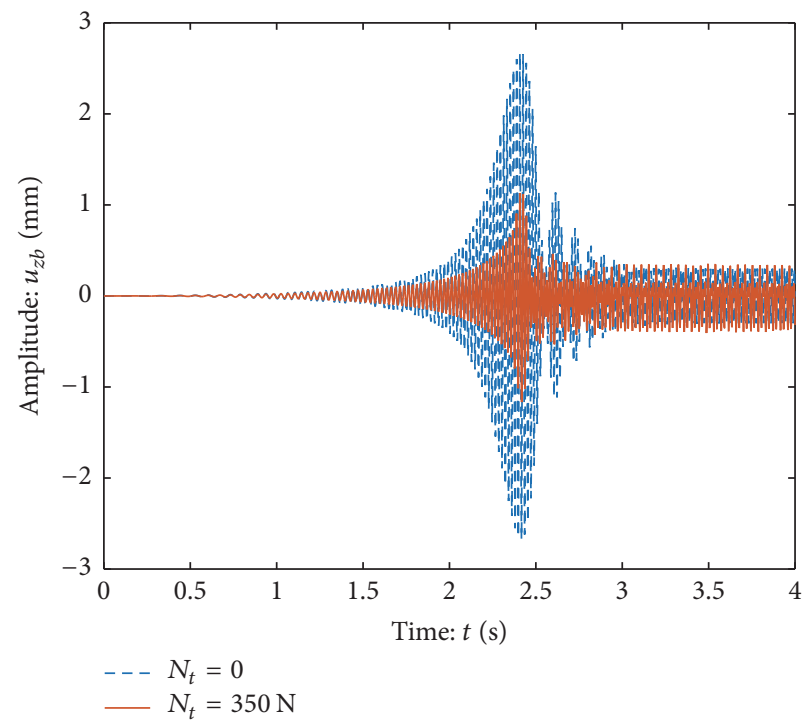

(d) $N_{t}=350 \mathrm{~N}$

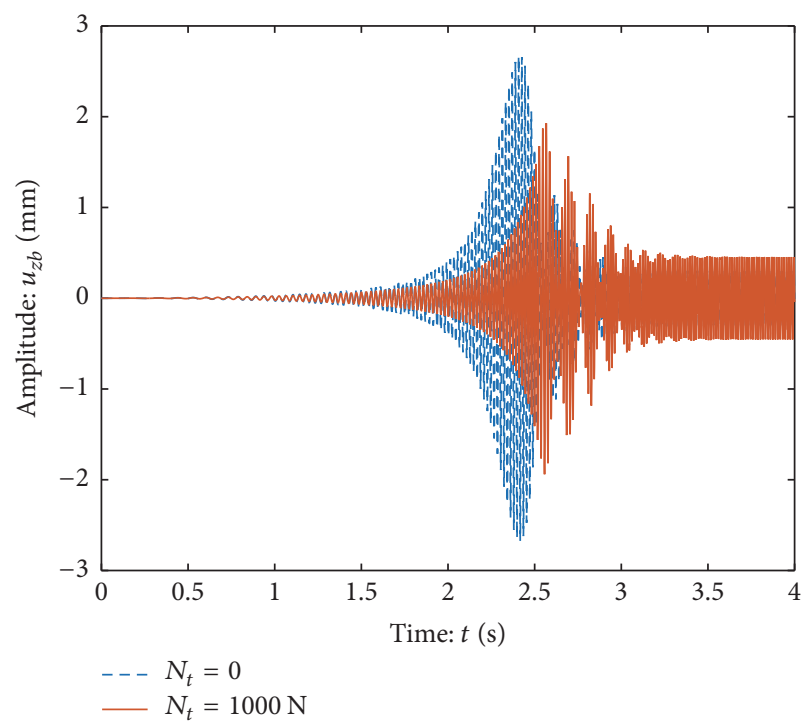

(f) $N_{t}=1000 \mathrm{~N}$

FIGURE 5: Bending vibration response of the tail shaft in the $x_{0}$ direction accelerating to exceed the critical speed. 

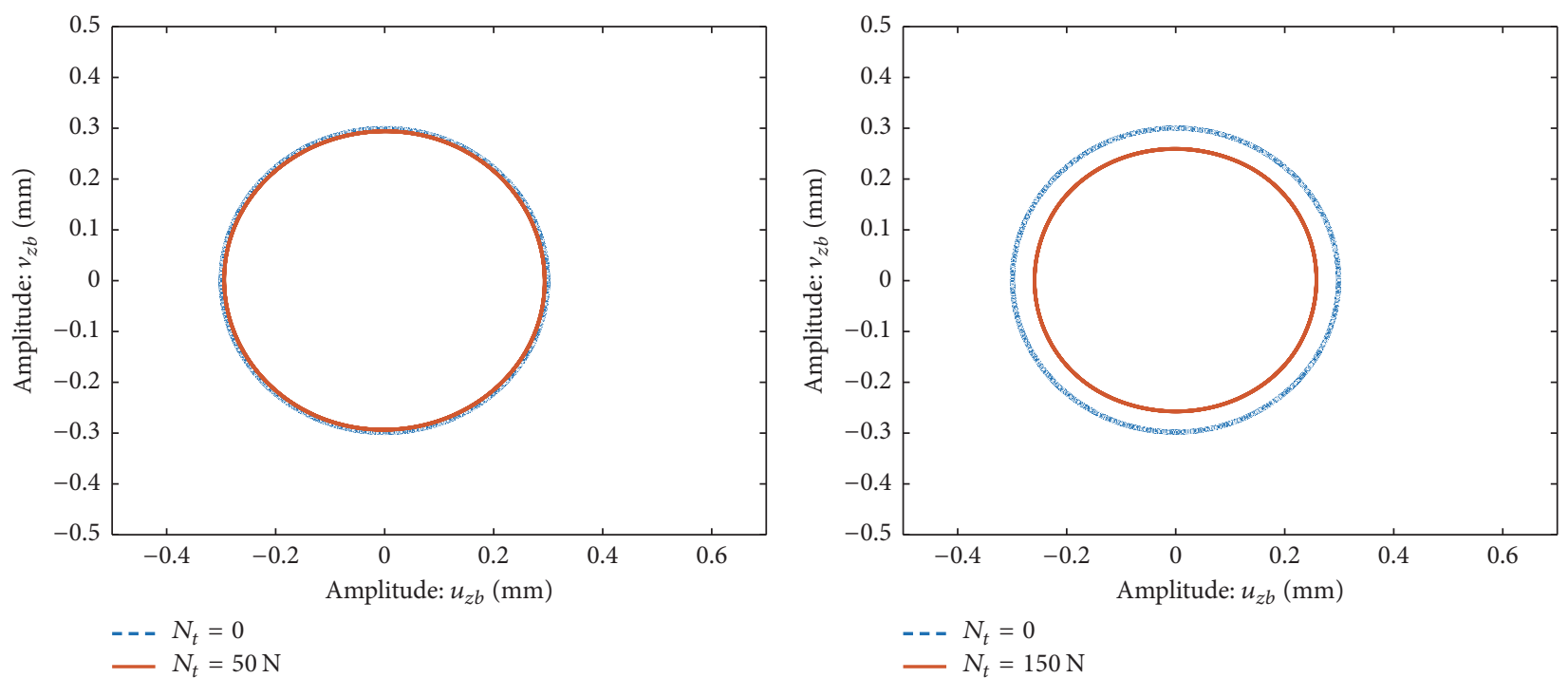

(a) $N_{t}=50 \mathrm{~N}$

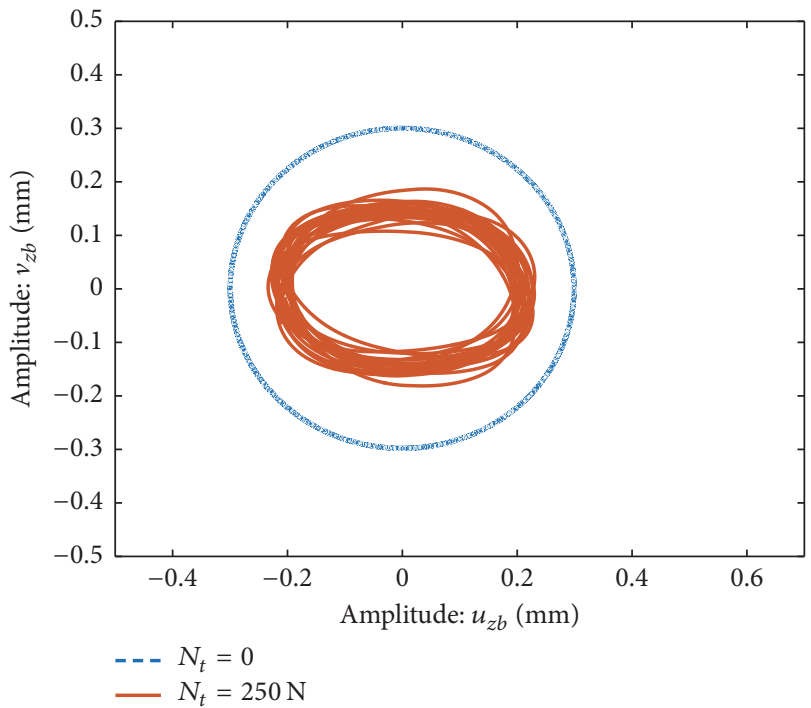

(c) $N_{t}=250 \mathrm{~N}$

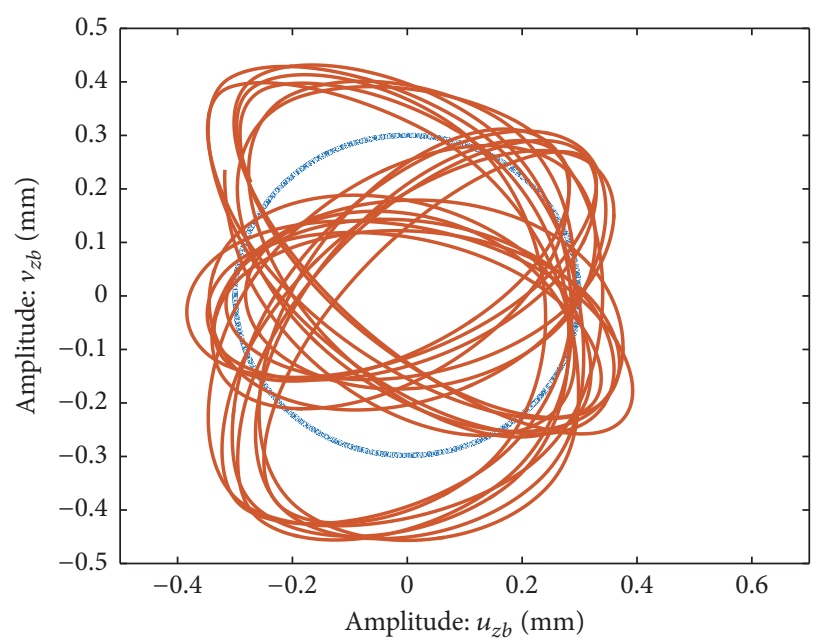

$---N_{t}=0$

$-N_{t}=450 \mathrm{~N}$

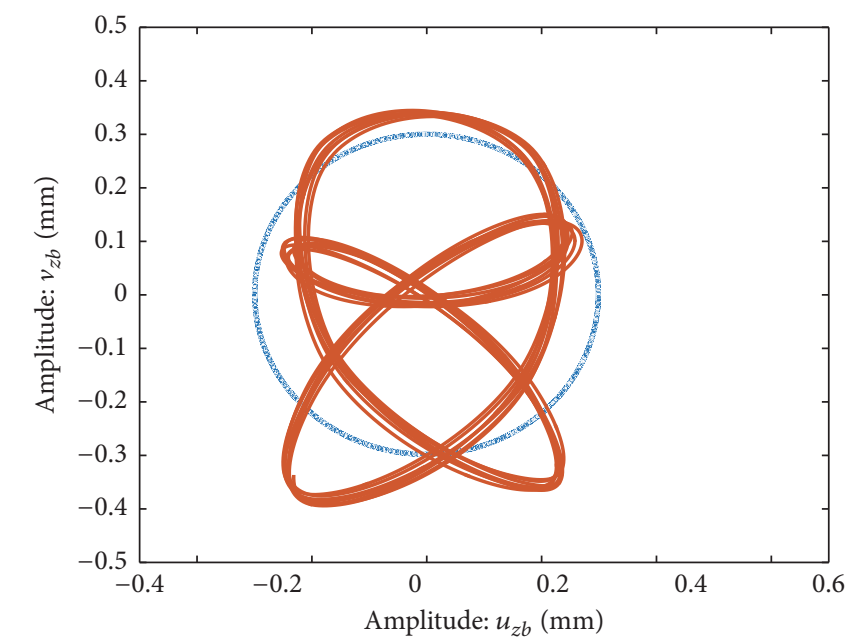

$---N_{t}=0$

$-N_{t}=350 \mathrm{~N}$

(d) $N_{t}=350 \mathrm{~N}$

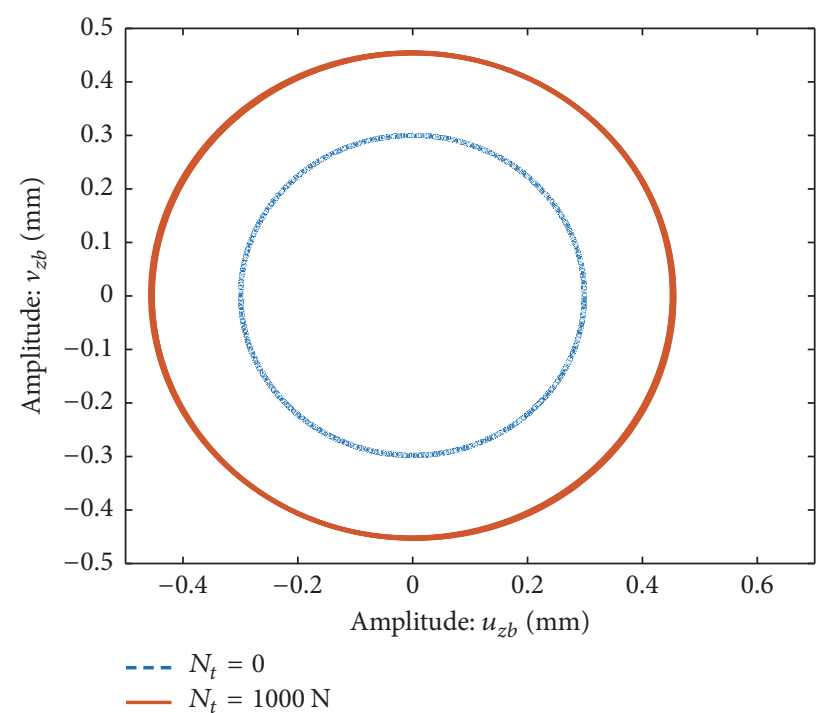

(e) $N_{t}=450 \mathrm{~N}$

(f) $N_{t}=1000 \mathrm{~N}$

FigURE 6: Center track of the tail shaft at operating speed. 


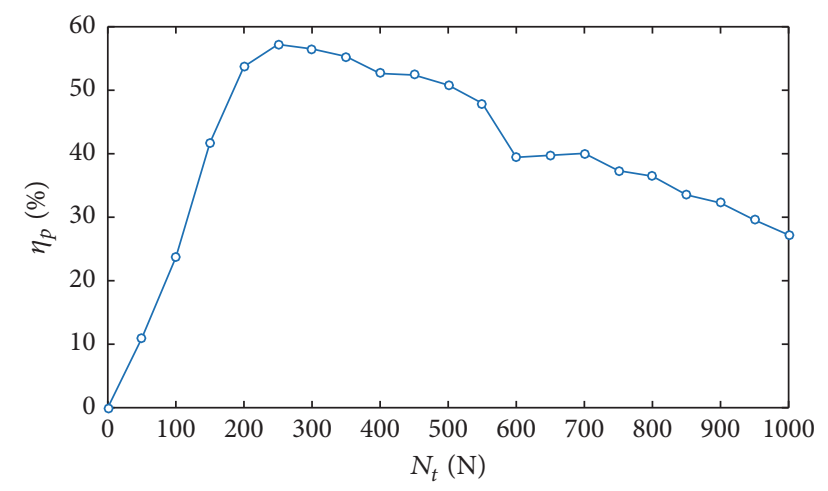

Figure 7: Relationship between the control force $N_{t}$ and the peak vibration-reduction ratio $\eta_{p}$.

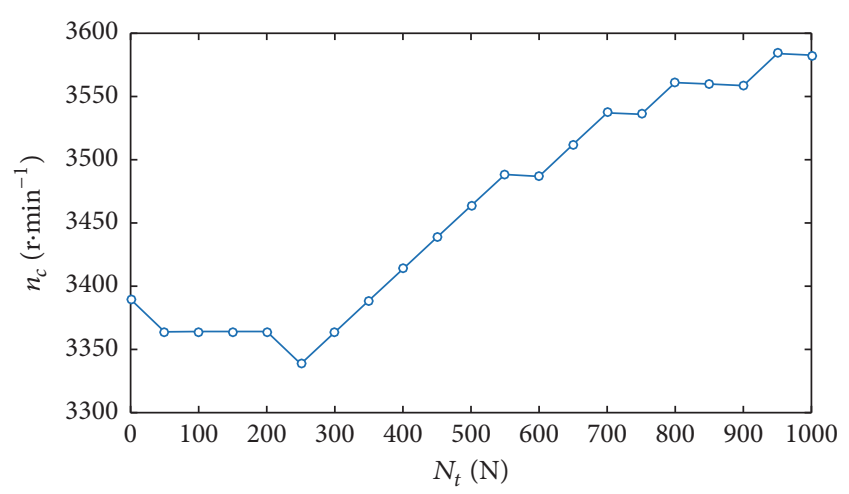

FIGURE 8: Relationship between the control force $N_{t}$ and the critical speed of the rotation $n_{c}$.

Considering the results above, we suggest that there is an optimal control parameter for the bending vibration suppression of the flexible multispan shaft with an SMSS. For the helicopter tail shaft in this section, there is a constant optimal control force: $N_{\text {topt }}=250 \mathrm{~N}$. This optimal control force is independent of whether it is needed to suppress the peak amplitude accelerating over the critical speed, to reach a steady state at the operating speed, or to let the critical speed of the tail shaft change away from its operating speed.

\section{Rotor Test}

4.1. Test Equipment. In order to verify the effect of the bending vibration suppression of the SMSS on the flexible multispan shaft, a conceptual structure of the SMSS was designed. Subsequently, a rotor test for vibration suppression was carried out on the multispan shaft test-setup. The arrangement of the test equipment is shown in Figure 9. Two elastic rubber rings were installed on the outer rings of the bearings in the elastic supports I and II, and for the rigid support III a steel ring was used. An auxiliary support was installed beside the elastic support II. These two represent the Smart Spring support. An eddy current sensor was set to measure the radial displacement of the shaft surface in the vertical direction, and the real-time speed of the shaft was measured with an infrared speed sensor.
TABLE 2: Support parameters of the test-setup.

\begin{tabular}{lc}
\hline Properties & Value/unit \\
\hline$k_{1}$ & $1.7 \times 10^{5} /\left(\mathrm{N} \cdot \mathrm{m}^{-1}\right)$ \\
$c_{1}$ & $20 /\left(\mathrm{N} \cdot \mathrm{s} \cdot \mathrm{m}^{-1}\right)$ \\
$k_{2}$ & $1.4 \times 10^{5} /\left(\mathrm{N} \cdot \mathrm{m}^{-1}\right)$ \\
$c_{2}$ & $22 /\left(\mathrm{N} \cdot \mathrm{s} \cdot \mathrm{m}^{-1}\right)$ \\
$k_{3}$ & $5 \times 10^{7} /\left(\mathrm{N} \cdot \mathrm{m}^{-1}\right)$ \\
$c_{3}$ & 0 \\
$k^{\prime}{ }_{2}$ & $1.67 \times 10^{7} /\left(\mathrm{N} \cdot \mathrm{m}^{-1}\right)$ \\
$c^{\prime}{ }_{2}$ & 0 \\
$\mu_{d}$ & 0.1 \\
$\mu_{s}$ & 0.15 \\
\hline
\end{tabular}

The detailed structure of the SMSS in the test-setup is shown in Figure 10. Three piezoelectric ceramics are put inside the main body of the PZTA. The adjustment nuts are used to apply prestress and fine-tune the gap between the two friction disks. The piezoelectric ceramics can be supplied with voltage from $0 \mathrm{~V}$ to $150 \mathrm{~V}$. When they are activated, the PZTA expands to push the two friction disks. As a result, the auxiliary support is coupled with the main support to change its radial stiffness and damping, so that the purpose of the vibration control can be achieved.

We obtained the support parameters for the test-setup in Table 2 via a load test. The radial stiffness of the elastic supports I and II is very small compared to other supports because of the elastic rubber rings. The auxiliary support would be deformed in the axial direction when the PZTA is activated. We measured the axial displacement of the auxiliary support for different control voltages. We then measured the axial stiffness of the auxiliary support $\left(k^{\prime}{ }_{a}\right.$ $=8.9 \times 10^{6} \mathrm{~N} \cdot \mathrm{m}^{-1}$ ). Then, the control force $N_{t}$ for the corresponding control voltage was obtained by multiplying these two quantities. As shown in Figure 11, the control force $N_{t}$ and the control voltage have a linear relationship, generally. When the control voltage reaches $150 \mathrm{~V}$, the control force reaches the maximum $N_{t \max }=447 \mathrm{~N}$. The theoretical maximum output force generated by the PZTA is very large $(2000 \mathrm{~N})$, but the maximum deformation in axial direction is very limited ( $65 \mu \mathrm{m}$ in axial direction). This means the effective control force $N_{t}$ is mainly related to the axial stiffness of the auxiliary support, and there is still much room for growth.

4.2. Test Results and Analysis. The shaft in the rotor setup starts to accelerate from rest with the angular acceleration $\alpha$ $=55 \mathrm{rad} / \mathrm{s}^{2}$, and it reaches its operating speed of $4200 \mathrm{RPM}$ after $8 \mathrm{sec}$. Subsequently, the shaft maintains its speed of rotation. The displacement responses of the point on the shaft surface for different control voltages were measured (see Figure 12). The amplitude reaches the first peak at 3229 RPM (see Figure 12(a)), and it no longer reaches a second clear peak until operating speed is reached. Hence, the first critical speed of the shaft is 3229 RPM.

The peak amplitude of the shaft decreases significantly when the PZTA is activated (see Figures 12(b)-12(f)). The 


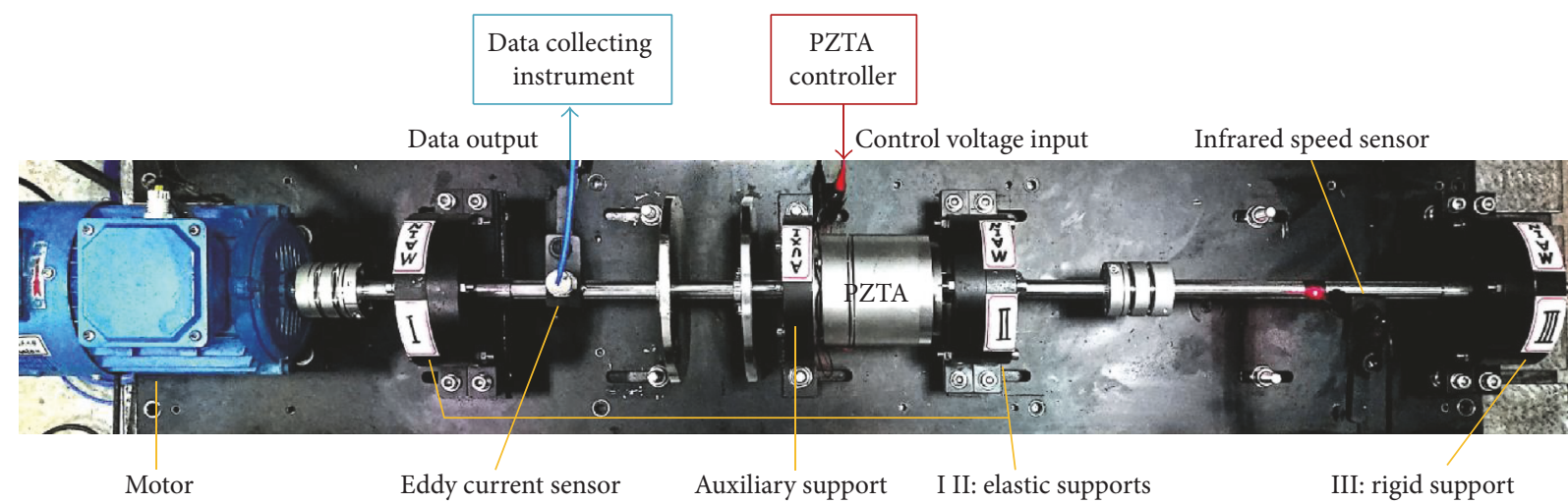

FIGURE 9: Multispan shaft test-setup with a Smart Spring support.

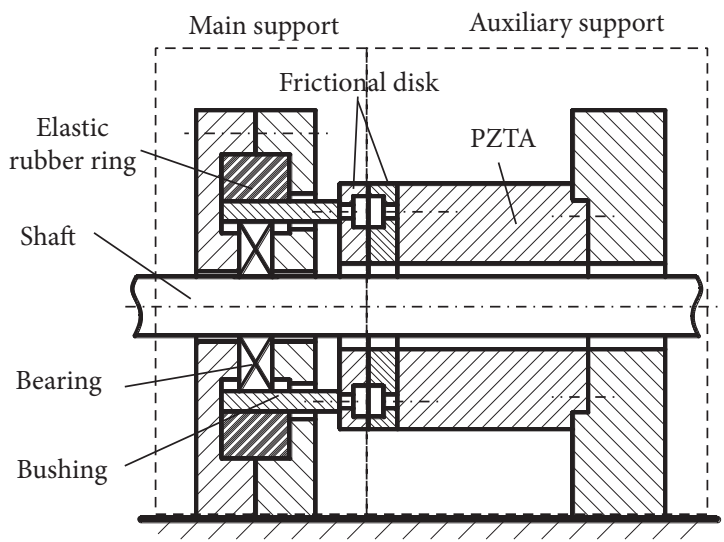

(a) General structure

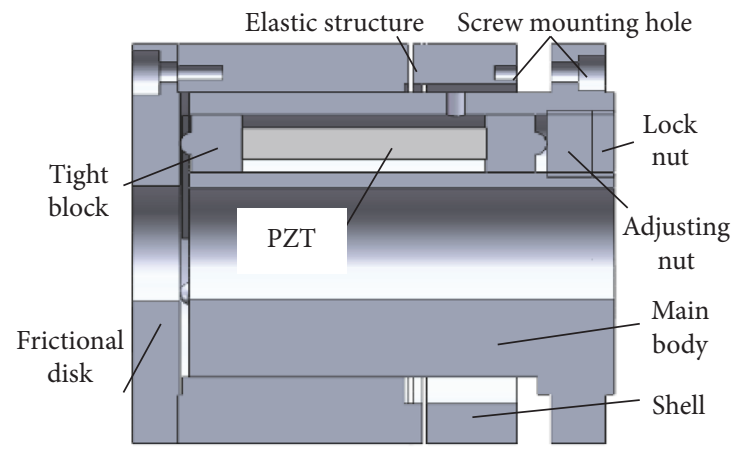

(b) Structure of PZTA

FIGURE 10: Structure of the Smart Spring support.

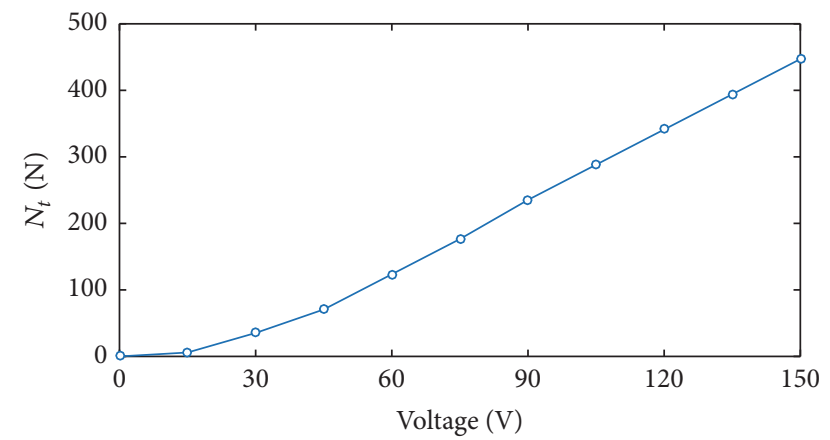

FIGURE 11: Relationship between the control voltage and the control force $N_{t}$ in the SMSS.

peak vibration-reduction ratio $\eta_{p}$ keeps increasing with growing control voltage (see Figure 13). The initial increase of $\eta_{p}$ is not very clear because of the gap between the friction disks. When the control voltage reaches $150 \mathrm{~V}, \eta_{p}$ reaches its maximum $45.2 \%$. Compared with Figure 7, the optimal control parameter appears at the maximum value. This is because the radial stiffness of the auxiliary support in the testsetup $\left(k_{2}^{\prime}=1.67 \times 10^{7} \mathrm{~N} \cdot \mathrm{m}^{-1}\right)$ is much greater than that in the example in the previous section $\left(k_{3}^{\prime}=1 \times 10^{5} \mathrm{~N} \cdot \mathrm{m}^{-1}\right)$. This results in the fact that the maximum control force of the PZTA $\left(N_{t \max }=447 \mathrm{~N}\right)$ is not large enough to bond the two friction disks. Therefore, the peak vibration-reduction ratio, $\eta_{p}$, can be improved further by enhancing the effective control force of the test equipment.

The position of the peak amplitude shifts left first with increasing control voltage (see Figures 12(b)-12(f)). The critical speed $n_{c}$ of the shaft keeps decreasing with growing control voltage (see Figure 14). When the control voltage reaches $150 \mathrm{~V}, n_{c}$ reaches its minimum of $2995 \mathrm{RPM}$. The friction disks maintain a relative motion because the control force generated by the PZTA is not large enough for the radial stiffness of the auxiliary support. Therefore, the SMSS is in the state of Damping Control here, which leads to the reduction of $n_{c}$.

The previous numerical and experimental results suggest that the increase of the radial stiffness of the auxiliary support helps to improve the optimal control parameter (force or voltage) for the SMSS. In addition, we need the PZTA to generate enough control force to accomplish optimal control. The control force $N_{t}$ and the axial stiffness of the auxiliary support are directly related for the SMSS in the test-setup. Hence, it is necessary to improve the axial stiffness of the 


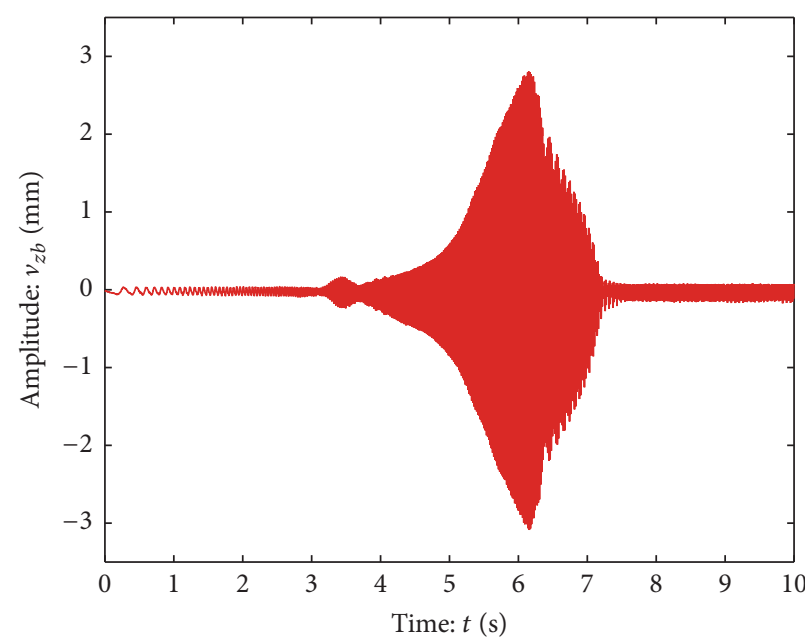

(a) Voltage $=0 \mathrm{~V} ; N_{t}=0 \mathrm{~N}$

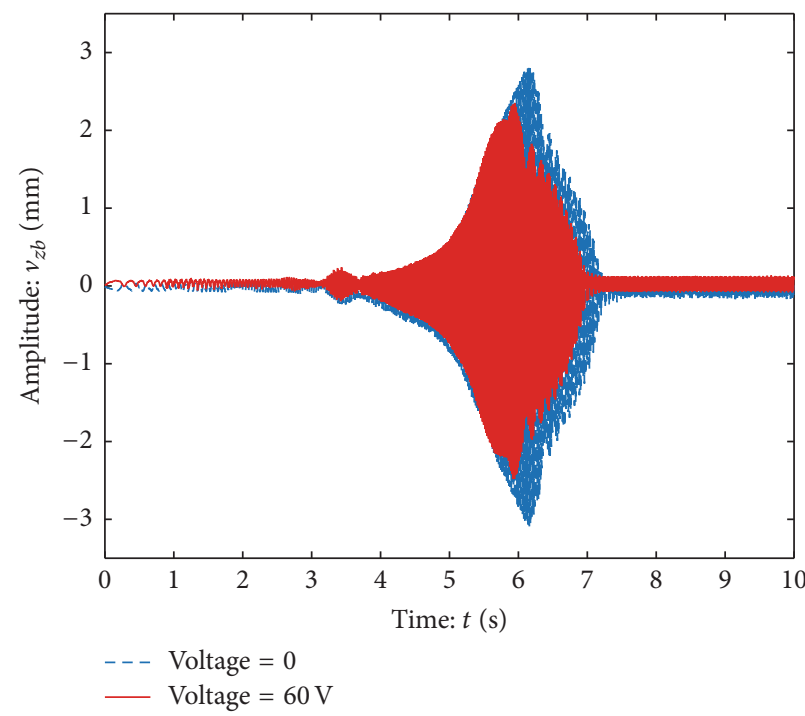

(c) Voltage $=60 \mathrm{~V} ; N_{t}=124 \mathrm{~N}$

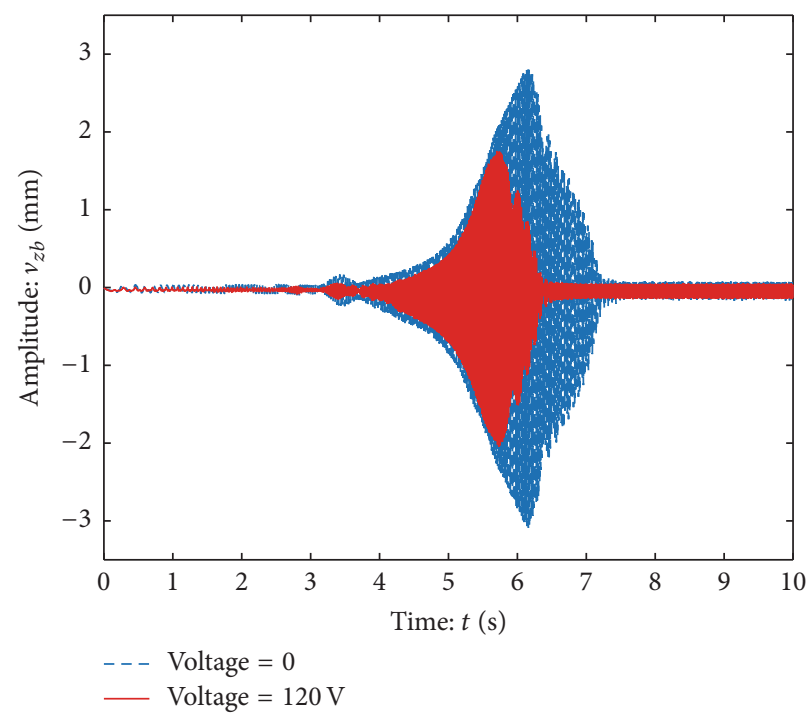

(e) Voltage $=120 \mathrm{~V} ; N_{t}=341 \mathrm{~N}$

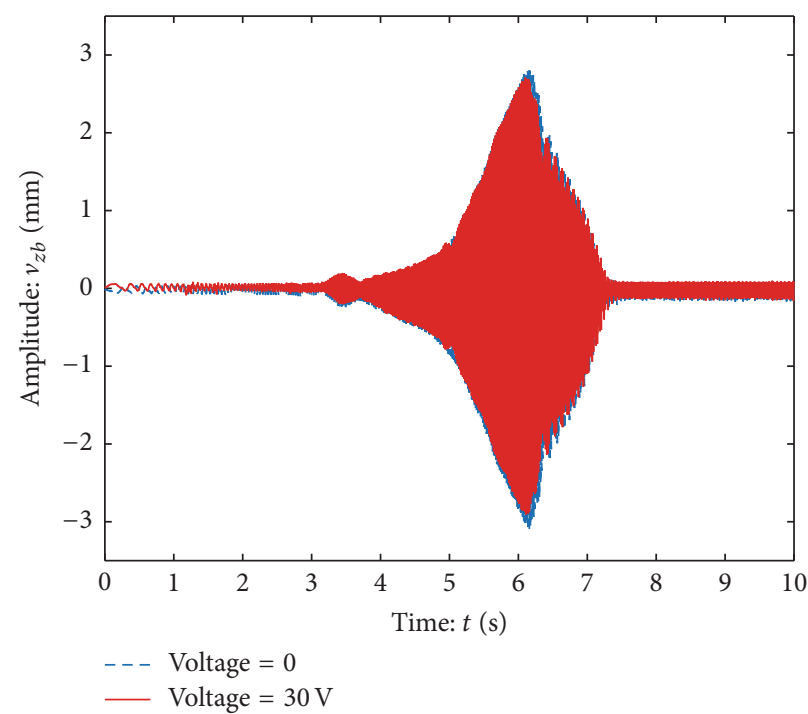

(b) Voltage $=30 \mathrm{~V} ; N_{t}=35 \mathrm{~N}$

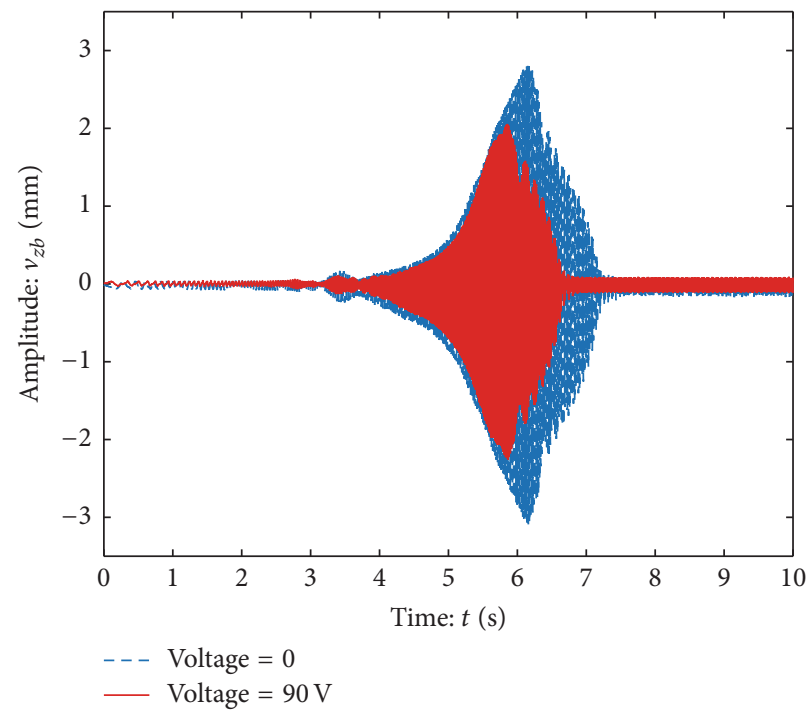

(d) Voltage $=90 \mathrm{~V} ; N_{t}=235 \mathrm{~N}$

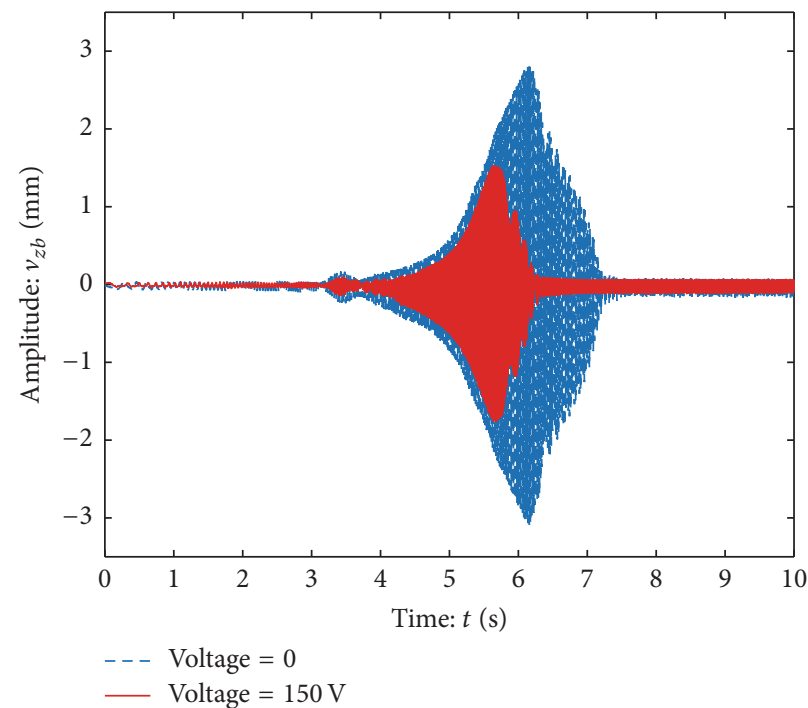

(f) Voltage $=150 \mathrm{~V} ; N_{t}=447 \mathrm{~N}$

FIGURE 12: The vibration response of the shaft system for different control voltages. 


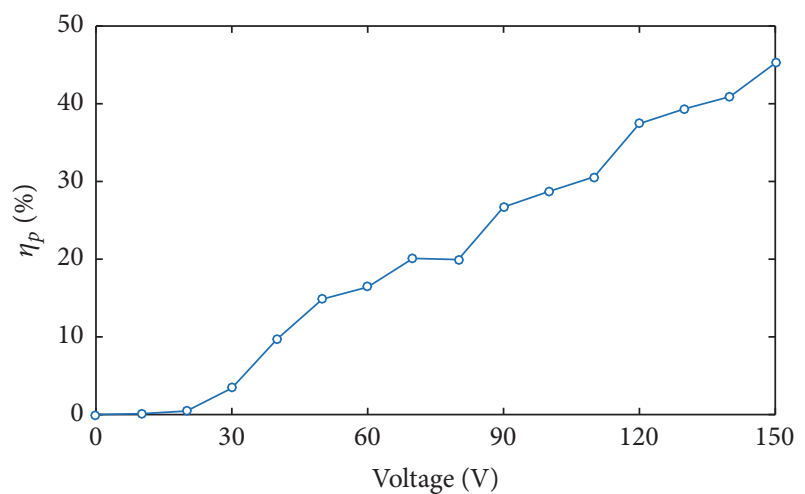

FIGURE 13: The peak vibration-reduction ratio $\eta_{p}$ as a function of the control voltage.

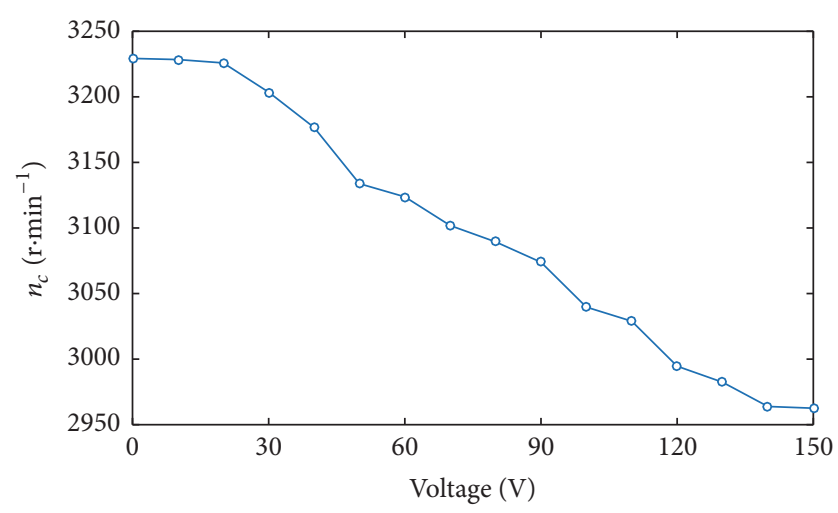

FIgURE 14: The critical speed of rotation $n_{c}$ as a function of the control voltage.

auxiliary support. The axial stiffness of the auxiliary support in Figure 10 is closely related to its radial stiffness, and these two are all dependent on the stiffness of the seat of the auxiliary support. Therefore, we suggest that the increase of the overall structural stiffness of the auxiliary support contributes to the improvement of damping of the SMSS.

\section{Conclusion}

In this paper, a new method for bending vibration suppression of a flexible multispan shaft based on Smart Spring support is investigated. The main conclusions are as follows: (a) The SMSS has a strong effect on the bending vibration suppression of the flexible multispan shaft when it exceeds its critical speed. (b) When the SMSS is in the state of Damping Control, it has better vibration suppression effect than that of Rigidity Control. There exists an optimal control force under the Damping Control state, which causes the peak vibration-reduction ratio $\eta_{p}$ to reach its maximum. (c) For the structural design of the SMSS, the overall structural stiffness can be increased, so that the maximum control force $N_{t \max }$ of the SMSS can reach, or get close to, its optimal control force $N_{\text {topt }}$.

\section{Conflicts of Interest}

The authors declare that they have no competing interests.

\section{Acknowledgments}

This research work is supported by the National Natural Science Foundation of China (nos. 51375226 and 51505215).

\section{References}

[1] L. I. Wenzhong, "Review on vibration control technology of high-speed rotor system," Journal of Mechanical Strength, vol. 27, no. 1, pp. 044-049, 2005.

[2] W. Qu, J. Sun, and Y. Qiu, "Active control of vibration using a fuzzy control method," Journal of Sound \& Vibration, vol. 275, no. 3-5, pp. 917-930, 2004.

[3] G. Song, V. Sethi, and H.-N. Li, "Vibration control of civil structures using piezoceramic smart materials: a review," Engineering Structures, vol. 28, no. 11, pp. 1513-1524, 2006.

[4] V. Wickramasinghe, C. Yong, D. Zimcik, T. Harold, and F. Nitzsche, "Smart spring: a novel adaptive impedance control approach for active vibration suppression applications," in Proceedings of the Smart Structures and Materials 2004-Smart Structures and Integrated Systems, vol. 5390, pp. 359-369, March 2004.

[5] M. Ahmadian and A. P. DeGuilio, "Recent advances in the use of piezoceramics for vibration suppression," Shock \& Vibration Digest, vol. 33, no. 1, pp. 15-22, 2001.

[6] H. Gu and G. Song, "Active vibration suppression of a flexible beam with piezoceramic patches using robust model reference control," Smart Materials \& Structures, vol. 16, no. 4, pp. 14531459, 2007.

[7] A. Nikkhoo, "Investigating the behavior of smart thin beams with piezoelectric actuators under dynamic loads," Mechanical Systems \& Signal Processing, vol. 45, no. 2, pp. 513-530, 2014.

[8] F. Nitzsche, D. D’Assunção, and C. De Marqui Junior, "Aeroelastic control of non-rotating and rotating wings using the dynamic stiffness modulation principle via piezoelectric actuators," Journal of Intelligent Material Systems and Structures, vol. 26, no. 13, pp. 1656-1668, 2015.

[9] G. Oxley, F. Nitzsche, and D. Feszty, "Smart spring control of vibration on helicopter rotor blades," Journal of Aircraft, vol. 46, no. 2, pp. 692-696, 2009.

[10] Nitzsche and Fred, "The use of smart structures in the realization of effective semi-active control systems for vibration reduction," Journal of the Brazilian Society of Mechanical Sciences \& Engineering, vol. 34, pp. 371-377, 2012.

[11] F. Nitzsche, D. Feszty, C. Grappasonni, and G. Coppotelli, "Whirl-tower open-loop experiments and simulations with an adaptive pitch link device for helicopter rotor vibration," in Proceedings of the 54th AIAA/ASME/ASCE/AHS/ASC Structures, Structural Dynamics and Materials Conference, April 2013.

[12] Arras, Melissa et al., "Identification of the Smart Spring properties from FRFs measurements," in Proceedings the of Aiaa/asce/ahs/asc Structures, Structural Dynamics, and Materials Conference, 2015.

[13] A. A. Cavalini, T. V. Galavotti, T. S. Morais, E. H. Koroishi, and V. Steffen, "Vibration attenuation in rotating machines 
using smart spring mechanism," Mathematical Problems in Engineering, vol. 2011, Article ID 340235, 14 pages, 2011.

[14] D. Ni and R. P. Zhu, "Influencing factors of vibration suppression performance for a smart spring device," Journal of Vibration \& Shock, vol. 31, no. 23, pp. 87-98, 2012. 


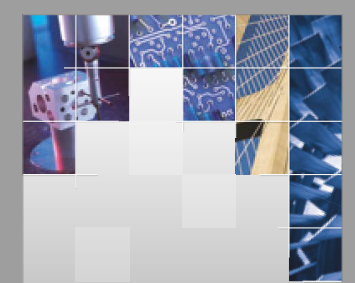

\section{Enfincering}
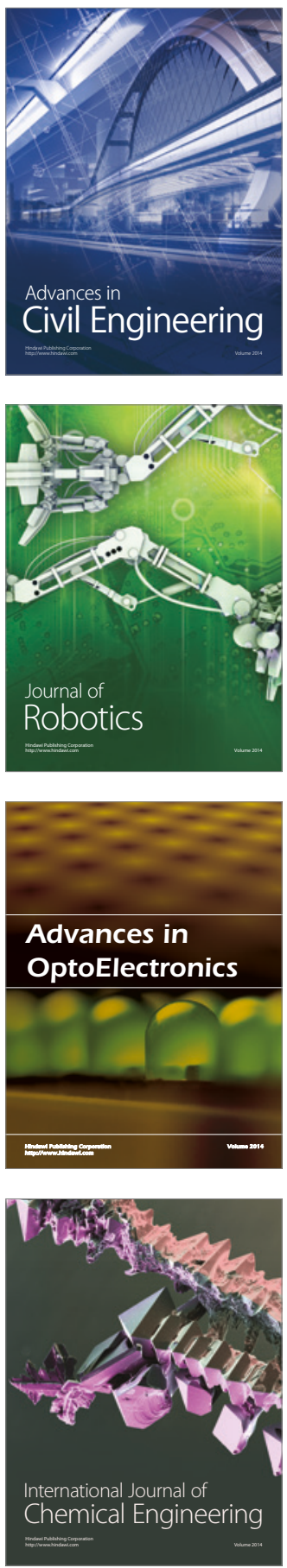

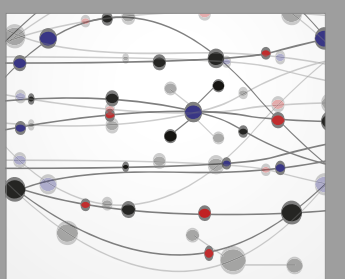

The Scientific World Journal

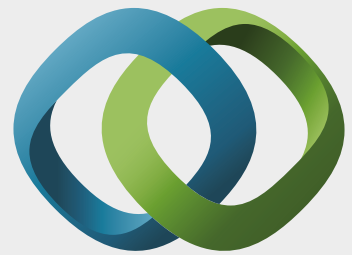

\section{Hindawi}

Submit your manuscripts at

https://www.hindawi.com
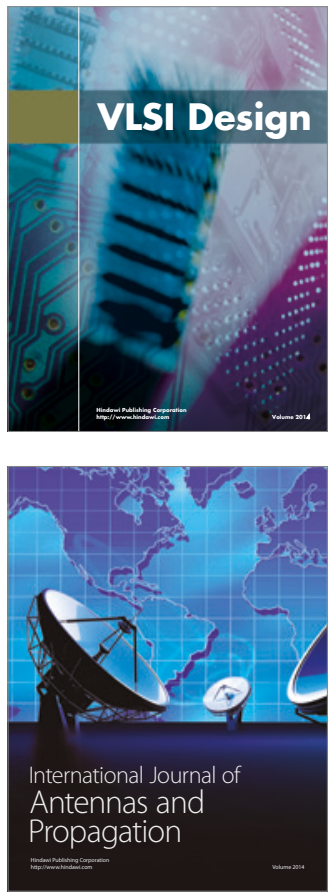

\section{Rotating}

Machinery
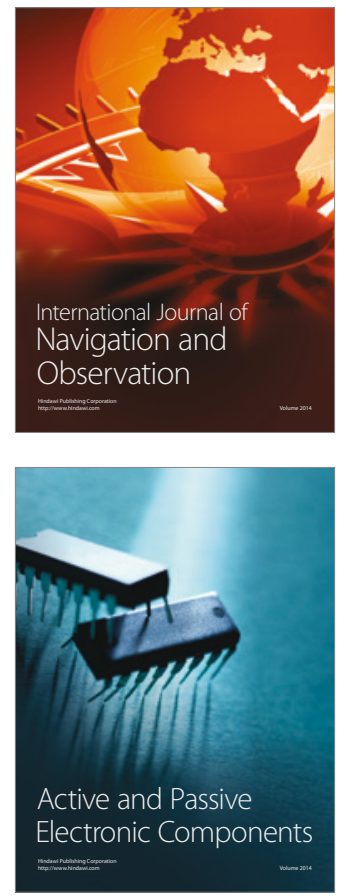
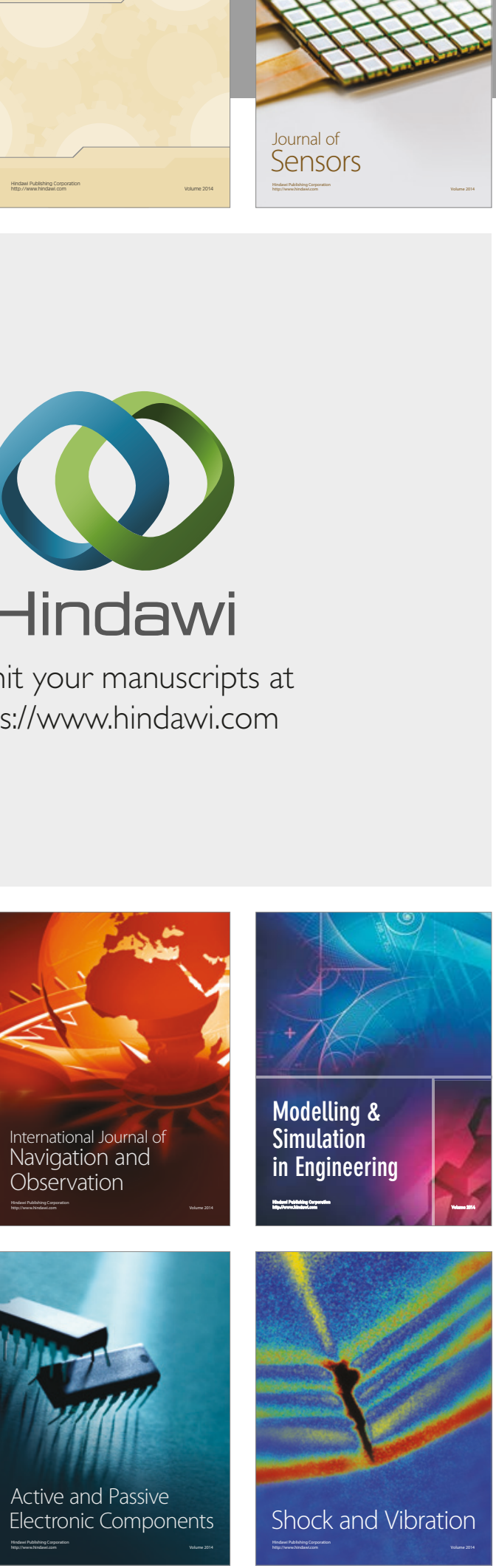
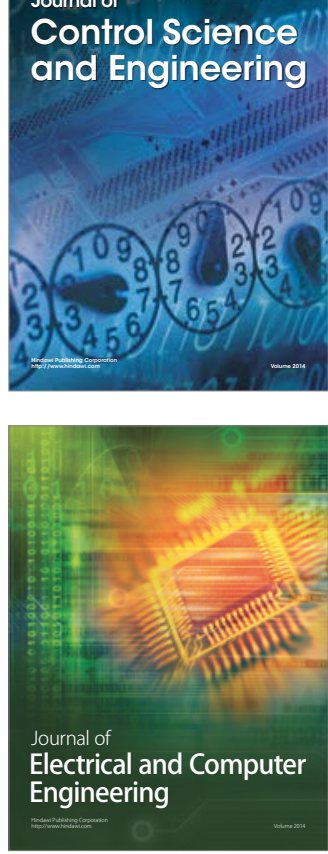

Distributed

Journal of

Control Science

and Engineering
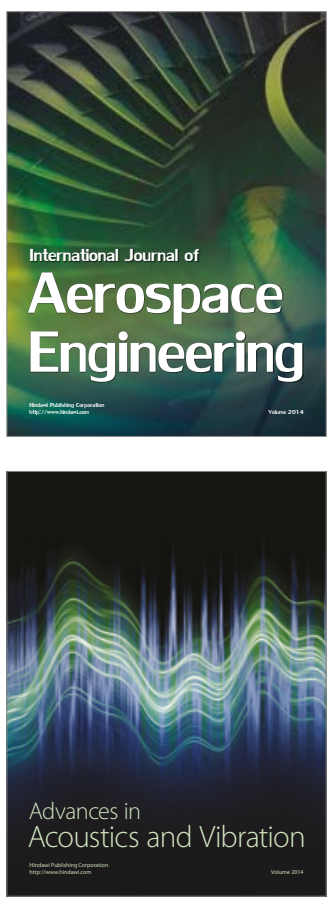

Sensor Networks 